\title{
Chemical functional groups of extractives, cellulose and lignin extracted from native Leucaena leucocephala bark
}

\author{
Rafidah Md Salim $^{1}$ D $\cdot$ Jahimin Asik $^{2} \cdot$ Mohd Sani Sarjadi $^{2}$
}

Received: 15 November 2019 / Accepted: 22 December 2020 / Published online: 23 January 2021

(c) The Author(s) 2021

\begin{abstract}
Bark from trees is considered a worthless raw material. However, this resource could be economically beneficial if utilized efficiently due to its rich chemical compounds. In this study, an ethanol toluene-soluble extractive, alpha-cellulose and lignin obtained from Leucaena leucocephala bark were characterized to determine their chemical functional groups. Based on FTIR spectral analysis, the results indicated that the bands of the functional groups of the extractive from the original bark remain unchanged; however, the absorbance intensity was found to be weaker in the group frequency and fingerprint regions. Removal of extractive, pectin, hemicellulose and lignin from the bark indirectly increased the strong absorbance intensity of cellulose. Broad peaks of $\mathrm{OH}$ stretching found in all spectra were assigned to the presence of phenolic $\mathrm{OH}$ and aliphatic structures for extractive and aromatic structures of lignin. It was revealed that aromatic functional groups were mainly found in the extractive, while water, carbonyl and ether were the dominant groups in cellulose, and methyl, methylene, carbonyl and carboxyl groups were enriched in lignin.
\end{abstract}

\section{Graphic abstract}

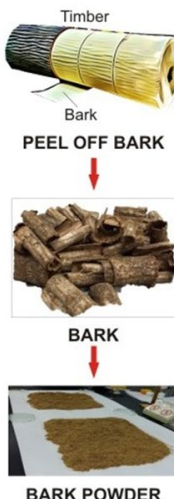

BARK POWDER
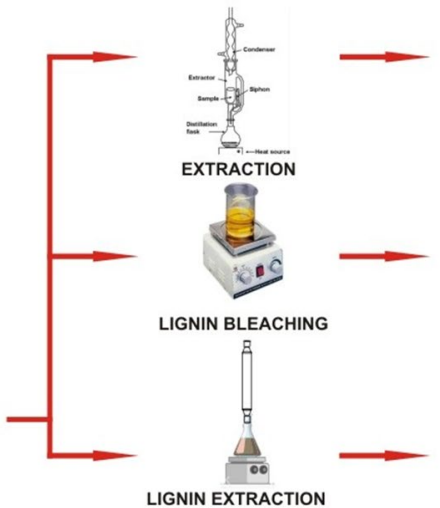

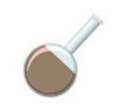

EXTRACTIVE

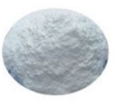

CELULLOSE

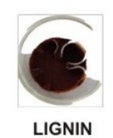

FTIR ANALYSIS
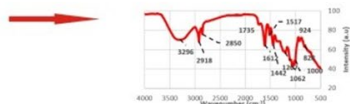

$\mathrm{C}=\mathrm{C} \quad \mathrm{C}-\mathrm{H} \quad-\mathrm{OH} \quad \mathrm{C}-\mathrm{O}$
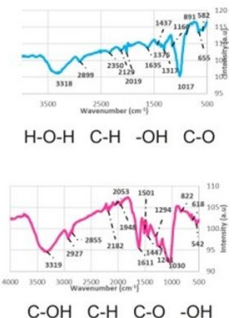

$\mathrm{C}-\mathrm{OH} \quad \mathrm{C}-\mathrm{H} \quad \mathrm{C}-\mathrm{O}-\mathrm{OH}$

Extended author information available on the last page of the article 


\section{Introduction}

Generally, barks from trees are regarded as worthless biomass residues and wastes and are mostly discarded, burned or used as fuel in the timber and sawmill industries (Lee and Lan 2006; Niokhor et al. 2009). However, some studies have reported that barks are rich in chemical compounds and could be beneficial to a variety of fields, ranging from the pharmaceutical industry to green polymers and bio-based materials (Pietarinen et al. 2006; Conde et al. 1996; Sen et al. 2010; Valentín et al. 2010). Utilization of these chemical compounds could also contribute to environmental conservation and the economy (Niokhor et al. 2009). All plant biomasses including barks, are rich in cellulose, hemicellulose, and lignin contents (Rutherford et al. 2012; Gonzalez-Vila et al. 2010). Bark, however, is different from other wood parts because it contains high amounts of water, organic soluble extractives, polyphenolics and lignin, as well as inorganic material referred to as ash (Fengel and Wegener 1984; Pereira et al. 2003). Thus, the characterization of chemical compounds and components in bark is vital before exploring their benefits and potential uses.

Infrared spectroscopy is currently one of the most important analytical techniques available to scientists in various fields that analyze almost any type of sample in the form of liquids, solutions, pastes, powders, films, fibers, gases and surfaces (Fan et al. 2012). The advantage of this tool is that it is fast, nondestructive, simple and low in cost (Roggo et al. 2007; Tsuchikawa 2007). In studies investigating lignocellulosic materials, FTIR spectroscopy was used to identify hydrogen bonds, chemical structures and compositions (Fan et al. 2012), certain functional groups or chemical bonds (Yang et al. 2012), phenolic compounds (Ghitescu et al. 2015) and aromatic compounds (Lee and Lan 2006). Apart from that, information obtained from FTIR analysis could also be used to optimize the experimental technique, to evaluate the effect of the operating conditions, to detect the presence of mineral matter and to determine gaseous reactions.

In another study, FTIR was also executed to investigate the differences in cellulose materials, especially in terms of crystallinity and hydrogen bonds of cellulose fibers in bark (Ciolacu et al. 2011). Furthermore, FTIR can examine the formation of inter- and intramolecular hydrogen bonds in cellulose. These properties strongly influence the physical properties of cellulose, including solubility (Kondo et al. 1994), hydroxyl reactivity (Kondo 1997) and crystallinity (Itagaki et al. 1997), and play an important role in the mechanical properties of cellulose (Kondo et al. 1994).

In Malaysia, Leucaena leucocephala is a native fast-growing tree often called 'Petai Belalang' by the local population. The genus Leucaena belongs to the family Leguminosae (flowering plants). This species has been discovered to possess much potential as timber plantation plants of Malaysia (MTIB 2017). Studies have found that the trunks and branches of L. leucocephala can be used as raw materials for composite products such as oriented strand boards (OSBs) (Wan Mohd Nazri et al. 2009), particle boards (Marzuki et al. 2011) and fiber boards (Ab. Rahman et al. 2018) This species is also a major raw material in mills for pulp and paper making (Kothiyal et al. 2012). It is known as a multipurpose tree and is widely used in gum production, furniture, construction timber, poles, etc. In fact, this species is now 
widely planted to restore land, control erosion and participate in water conservation, reforestation, and land management and has been used as a cover crop and green manure. The density of $L$. leucocephala bark is approximately $690 \mathrm{~kg} / \mathrm{m}^{3}$ (medium to hardwood class timber), which is representative of hardwood species of Malaysia (Ahmad et al. 2011; Babatunde 2008).

In this study, local L. leucocephala bark from the trunk was investigated. Bark from this portion normally produces a high percentage of wastes/residues while peeling off from the trunk. Fine barks were screened and mixed before the extraction was conducted. The extracts, cellulose, and lignin were further analyzed using FTIR methods. All peaks of the spectra produced from the analysis were identified, interpreted and compared to resolve their functional group activities.

\section{Materials and methods}

\section{Materials}

An eleven-year-old Leucaena leucocephala tree was harvested from the UMS campus, Kota Kinabalu, Sabah, Malaysia. It was first verified by botanist experts from the Forestry Division, UMS. The trunk was cut from the bottom up to the first branch. The trunk was transferred to a mill for further handling. The bark of the tree was initially peeled manually before being taken to the mill. In this step, the inner and outer bark was not separated. This is because the separation is quite difficult and costly. Furthermore, Xavier et al. (2012) caution that it is important to maintain these fractions to enhance the phenolic content of the skin and improve the properties of produced resins. Then, all the samples were transferred to the Wood Chemistry Laboratory for further processing.

\section{Preparation of samples}

The bark was gently washed under tap water to remove dirt before being air-dried in the laboratory at room temperature at $24{ }^{\circ} \mathrm{C}$ for $2-3$ weeks and protected from direct heat or sunlight. After being dried, the bark was chipped, flaked and pulverized into coarse powder using the laboratory grinder. The powder was then passed through a BS 500-um mesh sieve and retained in a 250-um mesh sieve to obtain 250-500 um particle sizes for extraction.

\section{Extraction of bark}

Bark powders were air-dried for several days until they reached the constant weights prior to chemical extraction. In laboratory work, the extractives were obtained by the ethanol toluene solubility method (ASTM D1105 2001), i.e., immersing the ground bark in ethanol-toluene solvent, rotor vaporizing and air-drying, while holocellulose 
was obtained by bleaching the bark with four times addition of $1.5 \% \mathrm{NaClO}_{2}$ to remove lignin and produce air-dried holocellulose. Subsequently, oven-dried alphacellulose was produced by further treating the holocellulose with $17.5 \% \mathrm{NaOH}$ and filtering the residues before washing them repeatedly with distilled water (ASTM D1103 2001). Then, lignin was obtained after filtering the lignin precipitates that occurred after the extractive-free bark was mixed with concentrated $\mathrm{H}_{2} \mathrm{SO}_{4}$ and heated with distilled water (ASTM D1106 2001).

\section{Separation of extractives}

Approximately $2 \mathrm{~g}$ of bark in a thimble (Whatman) was placed in a Soxhlet extraction flask. Extraction was performed with $150 \mathrm{ml}$ of ethanol solution. $427 \mathrm{ml}$ of toluene brought up to $1 \mathrm{~L}$ with the addition of ethanol. The solvent was mixed well. Extraction was conducted for $6 \mathrm{~h}$ with six siphoning steps. Subsequently, the flask was evaporated and dried in an oven at $103 \pm 2{ }^{\circ} \mathrm{C}$ for $1 \mathrm{~h}$ before being cooled and weighed. Then, the ethanol-toluene soluble bark was ready for FTIR analysis of extractives.

\section{Bleaching of lignin}

Approximately $2 \mathrm{~g}$ of air-dried extractive-free bark powder was weighed and transferred to a $250-\mathrm{ml}$ tall beaker. The flask was placed in a hot water bath at $70{ }^{\circ} \mathrm{C}$ after the addition of $100 \mathrm{ml}$ of distilled water, $1.5 \mathrm{~g}$ of sodium chlorite and $5 \mathrm{ml}$ of $10 \%$ acetic acid. The content was swirled every 5 min using a glass rod, making sure the flask was closed with a rounded flattened glass and the solution in the flask was just below the level of the water in the bath.

Approximately $5 \mathrm{ml}$ of $10 \%$ acetic acid was added after $30 \mathrm{~min}$, followed by the addition of $1.5 \mathrm{~g}$ of sodium chlorite for $30 \mathrm{~min}$ thereafter. This step was repeated 3 times, followed by a final addition of sodium chlorite. Subsequently, the suspension was cooled in an ice bath prior to filtering into a weighted crucible of porosity 1 . Residue (white in color) was finally washed with acetone after being washed with iced distilled water. The residue was transferred to a desiccator after air-drying for a day until it was free of acetone. The sample was ready for cellulose extraction.

\section{Extraction of cellulose}

Air-dried holocellulose from the previous step was placed into a $250-\mathrm{ml}$ tall beaker, and $15 \mathrm{ml}$ of $17.5 \% \mathrm{NaOH}$ was added. The solution was swirled using a magnetic stirrer for $1 \mathrm{~min}$. After the addition of $10 \mathrm{ml}$ of $17.5 \% \mathrm{NaOH}$, the solution was stirred for $45 \mathrm{~s}$. Next, the mixture was allowed to stand for $3 \mathrm{~min}$ after stirring for $15 \mathrm{~s}$ with the addition of up to $10 \mathrm{ml}$ of $17.5 \% \mathrm{NaOH}$. After $3 \mathrm{~min}$, another $10 \mathrm{ml}$ of $17.5 \% \mathrm{NaOH}$ was added and stirred for $2.5 \mathrm{~min}$. This step was repeated 3 more 
times (total time: $15 \mathrm{~min}$ ). The solution was allowed to stand for $30 \mathrm{~min}$ (total time: $45 \mathrm{~min}$ ) before the addition of $100 \mathrm{ml}$ of distilled water and swirling. Subsequently, the solution stood for $30 \mathrm{~min}$ (total time: $75 \mathrm{~min}$ ).

The mixture was filtered into a weighted fritted glass crucible (coarse porosity 3). The beaker and residue were rinsed with $25 \mathrm{ml}$ of $8.3 \% \mathrm{NaOH}$ solution before being washed with $650 \mathrm{ml}$ of distilled water at $20^{\circ} \mathrm{C}$. Filtration was stopped, and the crucible was filled with $2 \mathrm{~N}$ acetic acid for $5 \mathrm{~min}$. Filtration was continued, and the residue was rinsed with distilled water. The residue was oven-dried at $103 \pm 2{ }^{\circ} \mathrm{C}$ for $24 \mathrm{~h}$ before being cooled and weighed. Alpha-cellulose of bark was ready for FTIR analysis.

\section{Lignin extraction}

Approximately $1.4 \mathrm{~g}$ of air-dried extractive free bark powder was weighed out accurately and transferred to a 50-ml tall beaker. Fifteen milliliters of $72 \%$ sulfuric acid was added carefully with a pipette, and the mixture was stirred with a small glass rod (which was left in the beaker). The beaker was placed in a cold water immersion at $20{ }^{\circ} \mathrm{C}$ for $2 \mathrm{~h}$ with stirring every $10 \mathrm{~min}$. At the end of the period, the mixture was transferred to a $1 \mathrm{~L}$ Erlenmeyer flask containing $560 \mathrm{ml}$ of hot distilled water. A condenser reflux was connected to an Erlenmeyer flask, and the sample was boiled on a hot plate for $4 \mathrm{~h}$.

When refluxing was completed, the insoluble lignin was recovered by filtration through the known weight of the crucible (porosity 4). The residue was rinsed with $500 \mathrm{ml}$ of hot water and dried in an oven at $103 \pm 2{ }^{\circ} \mathrm{C}$ for $24 \mathrm{~h}$ before being cooled and weighed. The lignin content was ready for further FTIR analysis.

\section{FTIR analysis of barks}

Approximately $500 \mathrm{mg}$ of the fine powder of extractives was used for FTIR analysis to determine functional groups. The sample powder was placed directly on the diamond crystal or light path, and the reflectance spectra were collected. FTIR spectra were recorded on a Perkin-Elmer FTIR (model spectrum 100 series, USA) at ambient temperature, in the wavenumber range of 4000 to $400 \mathrm{~cm}^{-1}$ and at the resolution of $4 \mathrm{~cm}^{-1}$. Each spectrum was collected from an average of 4 scans, and the scan speed was $0.2 \mathrm{~cm}^{-1} \mathrm{~s}^{-1}$. The spectrum was interpreted to determine the functional group of extractives. This analysis was also conducted for cellulose and lignin. The spectrum from the original bark was used as a comparison.

\section{Results and discussion}

\section{FTIR analysis of Leucaena leucocephala stem bark}

In a previous study (Salim et al. 2019), extraction yields of L. leucocephala stem bark for extractives, cellulose and lignin were found to be $8.39 \%, 29.19 \%$ and 
$38.24 \%$, respectively. For chemical characterization, FTIR was used to determine functional groups of the components. The FTIR used infrared light as an energy source and the spectra produced used wavenumbers as units that were directly proportional to energy (a higher wavenumber corresponding to a higher energy); high intensity for FTIR typically means strong bonding, and weak absorption means weaker bonding of the chemical component. High intensity of these contents also means a high chemical content of the L. leucocephala extracted components. The spectrum of the original bark was used for comparison before and after extraction.

\section{Functional group of the main chemical components of bark}

The IR absorption spectra of the bark components (extractives, cellulose and lignin) and the original bark, recorded within the range of $4000-500 \mathrm{~cm}^{-1}$ are shown in Fig. 1.

The spectrum of the extractives demonstrates the highest peak with a sharp and broad shape followed by the spectra of lignin and cellulose, which mostly appear as small and tiny peaks. The original bark shows similarly shaped peaks with lignin and cellulose but at lower intensity. However, several peaks of the bark overlapped with the extractives. The majority of the peaks were sharp in the fingerprint region $\left(1800-500 \mathrm{~cm}^{-1}\right)$, while in the group frequency region $\left(1800-4000 \mathrm{~cm}^{-1}\right)$, common peaks were broader than the others. The intensity of the group frequency and fingerprint regions recorded in the range of 40.55 to 116.65 (a.u) shows that cellulose and lignin had stronger absorption bands and dominated the highest intensity

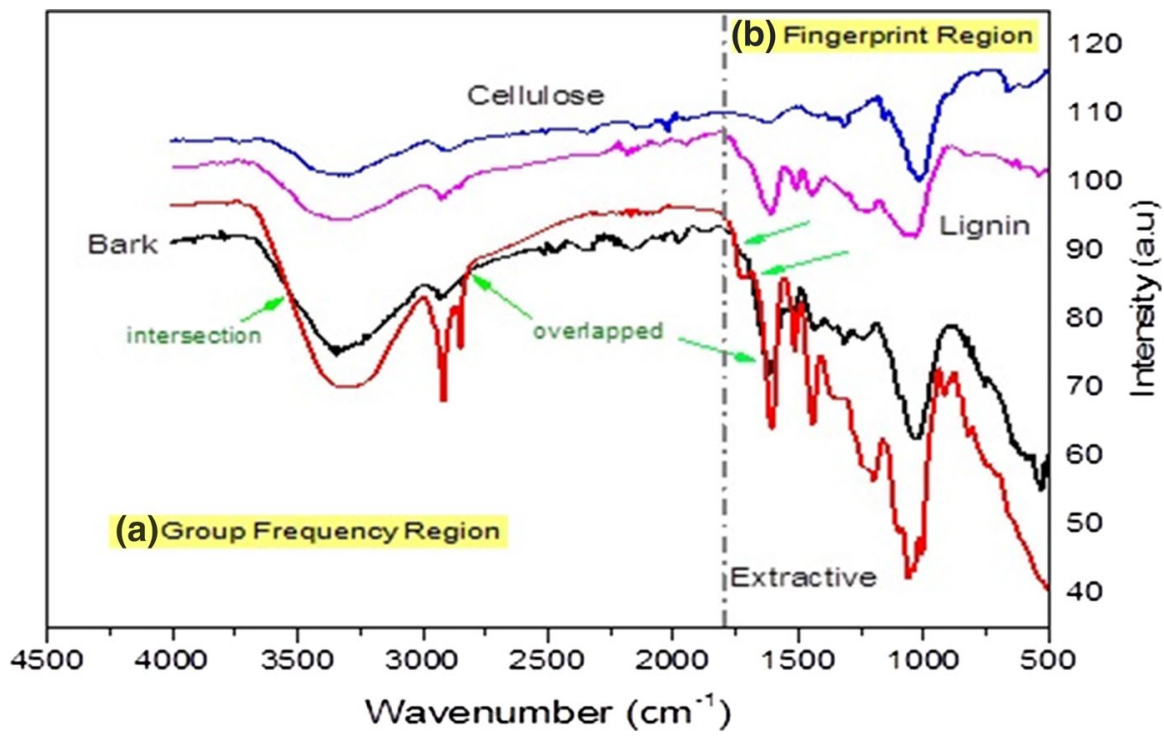

Fig. 1 FTIR spectra of chemical components of L. leucocephala bark a Group frequency region, b fingerprint region 
range at 100.24 to 116.65 (a.u) and at 92.14 to 107.40 (a.u), respectively. Moreover, extractives and the original bark had the lowest intensity ranges of 40.55-74.82 and 55.03-93.70 a.u, respectively.

Compared to the original bark, extractives showed broader peaks and intersected at $3538 \mathrm{~cm}^{-1}$ and $2871 \mathrm{~cm}^{-1}$ in the group frequency region. The peak of extractives also were sharp at $2918 \mathrm{~cm}^{-1}$ and, at the same time, showed a new sharp peak at $2850 \mathrm{~cm}^{-1}$ (Fig. 1). The appearance of these two sharp peaks revealed the formation of a new bond of the extractives.

In the fingerprint region, the overlapping peak between the original bark and extractives at $1753-1530 \mathrm{~cm}^{-1}$ indicates that the extractives have a similar composition after separation from the bark. The peaks are consistent with the same functionalities in the tannin of L. leucocephala bark in this study. However, an extraction reduces the absorbance intensity of extractives, even though bands of the functional groups of the extractives remain unchanged (Eberhardt et al. 2007) due to an opening of the cyclic ether structure of polyflavonoids (Soto et al. 2005).

Holocellulose (hemicellulose and alpha-cellulose) was obtained by bleaching the extractive-free bark using sodium chlorite to remove lignin. Hemicellulose is the most unstable component and easily decomposes in sodium hydroxide $(\mathrm{NaOH})$ solution. Thus, when holocellulose is treated with $17.5 \% \mathrm{NaOH}$, alpha-cellulose or cellulose is obtained. These processes contributed to the disappearance of three peaks of lignin in the cellulose spectrum, as illustrated in Fig. 1. The absence of lignin caused $\mathrm{OH}$ peaks to appear in the cellulose spectrum, indicating that hemicellulose and lignin were removed extensively during chemical treatment ( $\mathrm{Li}$ et al. 2009). Removal of extractives, pectin, hemicellulose and lignin from the original bark contributed indirectly to the increase in the intensity absorbance of cellulose, as shown in Fig. 1.

Lignin extraction involves the breakdown of cellulose structures by sulfuric acid. This concentrated acid is able to absorb water so strongly that it can breakdown cellulose into carbon and water and subsequently separate lignin as a precipitate.

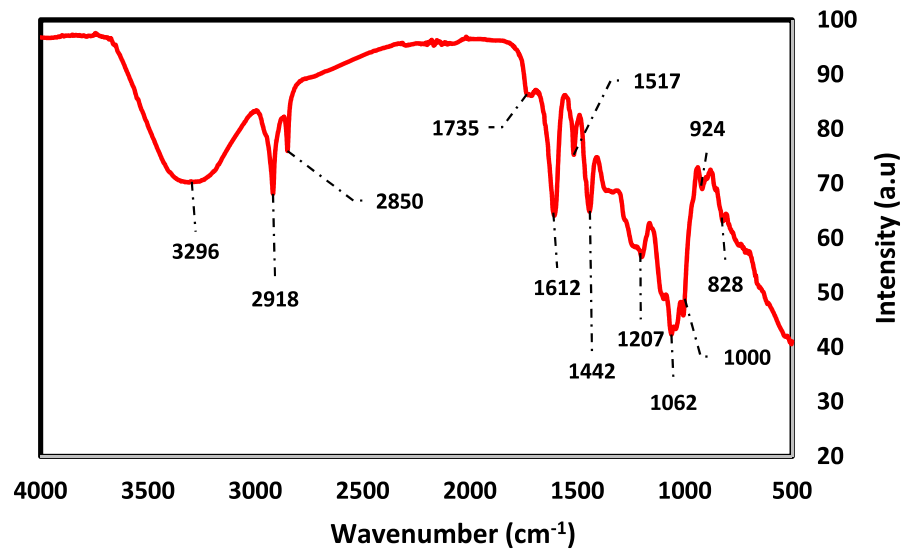

Fig. 2 FTIR spectra of extractives of L. leucocephala bark 
Figure 1 shows the absorbance intensity of lignin, which is lower than that of cellulose. Lignin intensity, however, was found to increase after the removal of extractives, pectin and hemicellulose (Ciolacu et al. 2011).

\section{Extractives of bark}

Figure 2 shows the functional group of FTIR spectra of the extractives of Leucaena leucocephala bark.

The broad and strong band at $3296 \mathrm{~cm}^{-1}$ was from the hydroxyl groups due to moisture in the bark. It is assigned as an $\mathrm{OH}$ stretch vibration in phenolic and aliphatic structures. This finding is almost similar to findings by previous researchers, who found that the band at $3300 \mathrm{~cm}^{-1}$ represents the stretching vibration of hydrogen bonded -OH groups in phenolic and aliphatic structures (Caron 2010; Williams and Fleming 1989). Feng et al. (2016) also found the broad spectra of $\mathrm{OH}$ stretching at the wavelengths of $3600-3200 \mathrm{~cm}^{-1}$, which may be attributed to the presence of phenolic $\mathrm{OH}$.

The two sharp and strong absorbed peaks that appeared at $2918 \mathrm{~cm}^{-1}$ (symmetric) and asymmetrically at $2850 \mathrm{~cm}^{-1}$ in Fig. 2 are attributed to the $\mathrm{CH}$ stretching vibration in the aromatic methoxyl group and methyl and methylene groups. Dirckx et al. (1992) also indicate that a similar value of the signal at $2850 \mathrm{~cm}^{-1}$ raised the $\mathrm{C}-\mathrm{H}$ stretching vibration in the aromatic methoxyl groups of lignin and methyl $\left(-\mathrm{CH}_{3}\right)$ and methylene $\left(-\mathrm{CH}_{2}\right)$ groups of side chains. This is similar to a study by Ferreira et al. (2013), who found that major peaks at 2920 and $2851 \mathrm{~cm}^{-1}$ are mainly attributed to the aliphatic chains of suberin, accounting for asymmetric and symmetric C-H stretching vibrations, respectively. Zhao et al. (2013) also imply that the main structures of the resins from bark changed to poly-aromatic structures during thermal degradation. The intensities of the peaks at 2914 and $2848 \mathrm{~cm}^{-1}$ were due to the aliphatic $\mathrm{CH}_{2}$ asymmetric stretch and aliphatic $\mathrm{CH}_{2}$ symmetric stretch, respectively. Lee and Lan (2006) also confirm that FTIR analysis showed that an aromatic compound is the main component in bark extracts.

The shoulder peak at $1735 \mathrm{~cm}^{-1}$ in Fig. 2 is assigned to the carbonyl group, $\mathrm{C}=\mathrm{O}$. Previous researchers found that the presence of $\mathrm{C}=\mathrm{O}$ stretching vibration at $1735 \mathrm{~cm}^{-1}$ corresponds essentially to the ester groups in suberin (Ferreira et al. 2013) and the carbonyl group (Eberhardt et al. 2007). Sinha and Rout (2009) also confirm the absorption bands at $1730 \mathrm{~cm}^{-1}$ assigned to $\mathrm{C}-\mathrm{O}$ stretching in the carboxyl and ketone groups. The peak centered at $1736 \mathrm{~cm}^{-1}$ is attributed to the acetyl and uronic ester groups of hemicellulose and $\rho$-coumaric acids of lignin and/or hemicellulose (Li et al. 2009). Moreover, Soto et al. (2005) suggest that the peaks between 1400 and $2000 \mathrm{~cm}^{-1}$ show the aromatic nature of the compound in the extract.

$\mathrm{C}=\mathrm{C}$ stretching in the aromatic ring appeared at $1612 \mathrm{~cm}^{-1}$ and $1442 \mathrm{~cm}^{-1}$ (Cheng et al. 2011; Feng et al. 2014). Figure 2 also shows that the intensities of the absorption bands at 1612,1517 and $1442 \mathrm{~cm}^{-1}$ were due to the aromatic stretching vibration. At $1442 \mathrm{~cm}^{-1}$, OH in-plane deformation absorption bands were weaker. The intensity of the bands is attributed to the carbohydrates that have diminished 
significantly in all extract spectra. This indicates that few carbohydrates have been extracted under the experimental conditions.

The presence of C-O-C stretch was detected at $1207 \mathrm{~cm}^{-1}$ (Dirckx et al. 1992; Schwanninger et al. 2004) as shown in Fig. 2. Moreover, the lower intensity of the peak was absorbed at $1062 \mathrm{~cm}^{-1}$ corresponding to $-\mathrm{CO}$ stretch vibration. Li et al. (2009) also confirm that the peak at $1061 \mathrm{~cm}^{-1}$ is associated with the $\mathrm{C}-\mathrm{O}$ stretching that appeared in all of the spectra. The cyclic nature of the ether was reflected by the signal located at $1030 \mathrm{~cm}^{-1}$, which was produced by the aliphatic $\mathrm{C}-\mathrm{O}$ stretching. However, Liu et al. (2010) declared that the region between 1000 and $1150 \mathrm{~cm}^{-1}$ corresponded to the strength vibration of $\mathrm{C}-\mathrm{OH}$ side groups and the $\mathrm{C}-\mathrm{O}-\mathrm{C}$ glycosidic bond vibration. Figure 2 shows the FTIR spectra of extractives of L. leucocephala bark. The band intensity detected at $1000 \mathrm{~cm}^{-1}$ is attributed to $\mathrm{C}-\mathrm{OH}$ side groups (Feng et al. 2016), while the peak at $924 \mathrm{~cm}^{-1}$ region is assigned to the $\mathrm{C}-\mathrm{H}$ bending vibration (Liu et al. 2011a). Absorbance at $828 \mathrm{~cm}^{-1}$ is attributed to the $-\mathrm{CH}$ bend in aromatics (Feng et al. 2016). The absorption peaks located at approximately $828 \mathrm{~cm}^{-1}$ are also attributed to $-\mathrm{C}-\mathrm{N}$ stretching vibrations of the amine groups (Shameli et al. 2012).

\section{Cellulose of bark}

Figure 3 shows a large and broader absorption band detected in the range of $3000-3750 \mathrm{~cm}^{-1}$ assigned to the stretching vibration of $\mathrm{O}-\mathrm{H}$ groups.

This finding is supported by Sathishkumar et al. (2013), who found that the region at approximately $3340 \mathrm{~cm}^{-1}$ is attributed to hydroxyl group $(\mathrm{OH})$ activities. Saravanakumar et al. (2013) also showed that the peak that appeared at $3342 \mathrm{~cm}^{-1}$ was due to the $\mathrm{OH}$ stretching of alpha-cellulose. The broad band in the $3600-3100 \mathrm{~cm}^{-1}$ region, which is due to the $\mathrm{OH}$ stretching vibration, gives considerable information concerning the hydrogen bands, which can be correlated with the scission of the intra- and inter-molecular hydrogen bonds (Ciolacu et al. 2011).

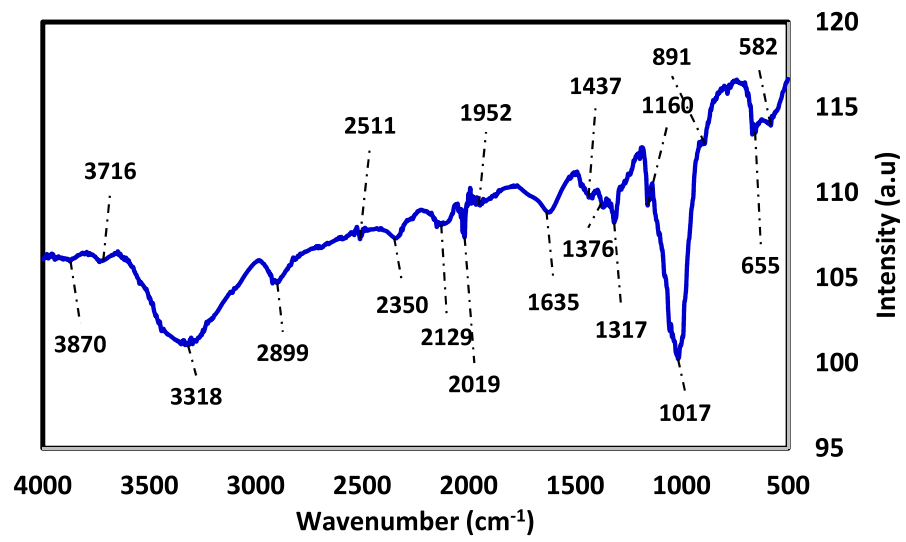

Fig. 3 FTIR spectra of cellulose of L. leucocephala bark 
The peak at $2899 \mathrm{~cm}^{-1}$ is attributed to the $\mathrm{C}-\mathrm{H}$ stretching vibration (Fig. 3). Ciolacu et al. (2011) found that the presence of amorphous cellulose samples can be further confirmed by the shift of the band from $2900 \mathrm{~cm}^{-1}$, which corresponded to the $\mathrm{C}-\mathrm{H}$ stretching vibration. The peak at $2848 \mathrm{~cm}^{-1}$ is associated with the $\mathrm{CH}_{2}$ groups of cellulose and hemicellulose (Fiore et al. 2014; Indran et al. 2014).

In Fig. 3, the peaks appearing at $2350 \mathrm{~cm}^{-1}$ are due to the presence of carbon dioxide, while the peaks at 2129 and $2019 \mathrm{~cm}^{-1}$ are assigned to the $\mathrm{C}=\mathrm{C}$ stretch vibration. The appearance of these three peaks might possibly be due to the delignification of bark during cellulose extraction. Li et al. (2009) believe that the peak was predominantly contributed by the aromatic $\mathrm{C}=\mathrm{C}$ stretching of the aromatic ring in the lignin since this peak disappeared in the other three spectra due to the removal of lignin. The band at the $1635 \mathrm{~cm}^{-1}$ region is attributed to the adsorbed water as reported by Liu et al. (2011a) for mulberry bark. The appearance of a tiny shoulder at $1437 \mathrm{~cm}^{-1}$ and the peak at $1376 \mathrm{~cm}^{-1}$ in Fig. 3 indicates the characteristic peaks of aromatic skeletal vibration (Liu et al. 2011a; Sun et al. 2005) and methoxyl vibration (Moran et al. 2008), due to the presence of small amounts of lignin. In addition, the FTIR absorption band at $1430 \mathrm{~cm}^{-1}$ was related to the symmetric $\mathrm{CH}_{2}$ bending vibration (Ciolacu et al. 2011). This band is also known as the "crystallinity band," and a decrease in its intensity reflects a reduction in the degree of crystallinity of the samples (Ciolacu et al. 2011). Subramanium et al. (2005) found that the peak at approximately $1427 \mathrm{~cm}^{-1}$ and $1371 \mathrm{~cm}^{-1}$ corresponds to $\mathrm{CH}_{2}$ and $\mathrm{CH}$ groups of cellulose (Belouadah et al. 2015). The tiny peak found at $1317 \mathrm{~cm}^{-1}$ as shown in Fig. 3, is attributed to the presence of the small amount of $\mathrm{C}-\mathrm{O}$ stretching vibration of the syringyl ring units (Ghitescu et al. 2015; Shi et al. 2011; Faix 1992), while the peak at $1158 \mathrm{~cm}^{-1}$ signifies the $\mathrm{C}-\mathrm{O}-\mathrm{C}$ groups of cellulose and hemicellulose (Seki et al. 2013; Belouadah et al. 2015). The sharp tiny peak located at $1160 \mathrm{~cm}^{-1}$ is linked to the $\mathrm{C}-\mathrm{O}-\mathrm{C}$ asymmetrical stretching.

Liu et al. (2010) state that the region between 1000 and $1150 \mathrm{~cm}^{-1}$ corresponds to the strength vibration and the $\mathrm{C}-\mathrm{O}-\mathrm{C}$ glycosidic bond vibration, and this is almost similar to the peak at $1160 \mathrm{~cm}^{-1}$ as evidenced in Fig. 3. The broad sharp peak absorbed at the $1017 \mathrm{~cm}^{-1}$ region as shown in Fig. 3 is attributed to the $\mathrm{C}-\mathrm{O}$ stretching vibration from the cellulose, which increased the peak intensity after the removal of pectin, hemicellulose and lignin (Liu et al. 2011b). Ciolacu et al. (2011) and $\mathrm{Li}$ et al. (2009) confirm that $897 \mathrm{~cm}^{-1}$ is associated with the $\mathrm{C}-\mathrm{H}$ rocking vibrations of cellulose, which appeared in all of the spectra. The features of the characteristic region $\left(1700-850 \mathrm{~cm}^{-1}\right)$ are due to the constituents of alpha-cellulose, lignin and hemicellulose (Khan et al. 2005; Miao et al. 2016). The band at $891 \mathrm{~cm}^{-1}$, shown in Fig. 3 corresponds to the $\mathrm{C}-\mathrm{H}$ rocking vibrations from the cellulose. However, the presence of a peak at approximately $898 \mathrm{~cm}^{-1}$ is associated with the $\mathrm{C}-\mathrm{O}$ groups, which are related to the $\beta$-glycosidic linkages (Reddy et al. 2014; Seki et al. 2013). The little peaks at approximately $662 \mathrm{~cm}^{-1}$ and $588 \mathrm{~cm}^{-1}$ correspond to the $\mathrm{C}-\mathrm{OH}$ bending (Fan et al. 2012; De Rosa et al. 2010). These similar peaks are also found at 655 and $582 \mathrm{~cm}^{-1}$, as illustrated in Fig. 3. 


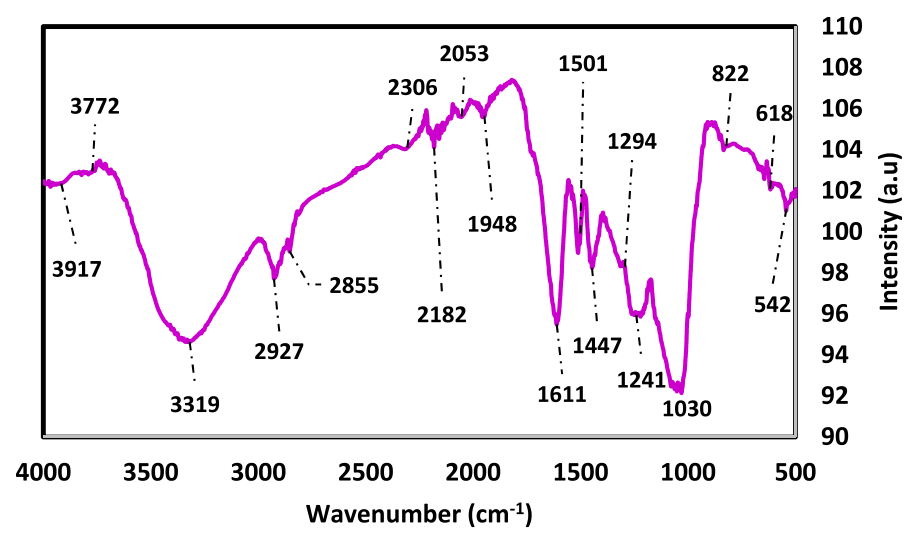

Fig. 4 FTIR spectra of lignin of L. leucocephala bark

\section{Lignin of bark}

Figure 4 shows the FTIR spectrum of the lignin L. leucocephala bark. The band at $3319 \mathrm{~cm}^{-1}$ is attributed to the $\mathrm{OH}$ groups in lignin. Guo et al. (2008) found that the broad band at $3412 \mathrm{~cm}^{-1}$ was dominated by the stretching vibrations of aromatic and aliphatic $\mathrm{OH}$ groups.

Peaks appearing at 2927 and $2855 \mathrm{~cm}^{-1}$ could possibly correspond to the $\mathrm{C}-\mathrm{H}$ stretching in the lignin molecules. Sahoo et al. (2011) found this chemical group at 2919 and $2849 \mathrm{~cm}^{-1}$, and Guo et al. (2008) found that the peaks at 2925 and $2849 \mathrm{~cm}^{-1}$ predominantly arose from the $\mathrm{C}-\mathrm{H}$ stretching in methyl of aromatic and methylene groups of side chains and aromatic methoxyl groups. Similar findings by El Mansouri and Salvado (2007) and Gosselink et al. (2004) indicated that $\mathrm{C}-\mathrm{H}$ stretch in methyl and methylene groups is present in regions between 3000 and $2800 \mathrm{~cm}^{-1}$.

The presence of three small peaks at 2182, 2053 and $1948 \mathrm{~cm}^{-1}$, as shown in Fig. 4, was attributed to the appearance of NCO from isocyanate groups. Schaber et al. (2004) found this functional group peak at $2167 \mathrm{~cm}^{-1}$. The strong and sharp peak at $1611 \mathrm{~cm}^{-1}$ was attributed to the aldehyde group of lignin. Wahab et al. (2010) also confirmed this group at $1616 \mathrm{~cm}^{-1}$. According to Gosselink et al. (2004), aromatic skeletal vibration bands were observed for all lignins at 1600 and $1500 \mathrm{~cm}^{-1}$ wavenumber ranges. Thus, the medium and sharp peaks found at $1501 \mathrm{~cm}^{-1}$ in Fig. 4 could be attributed to $\mathrm{CH}$ deformation (methyl and methylene), while the peak at $1447 \mathrm{~cm}^{-1}$ band could correspond to the aromatic skeletal vibration combined with $\mathrm{C}-\mathrm{H}$ in plane deformation. The peaks at 1460 , 1510 and $1600 \mathrm{~cm}^{-1}$ in the FTIR spectra are assigned to $\mathrm{C}-\mathrm{H}$ deformations (asymmetric in methyl, methylene and methoxyl group), the aromatic skeletal vibrations coupled with $\mathrm{C}-\mathrm{H}$ in plane deformations, and the aromatic skeletal vibrations, respectively (Tian et al. 2010). 
In Fig. 4, lignin structures at 1294 and $1241 \mathrm{~cm}^{-1}$ wavenumber ranges are possibly due to the $\mathrm{C}=\mathrm{O}$ stretching of syringyl and guaiacyl ring, respectively. Shi et al. (2011) confirmed this compound at 1280 and $1120 \mathrm{~cm}^{-1}$, and Guo et al. (2008) affirmed this absorption at $1329 \mathrm{~cm}^{-1}$ (syringyl) and $1217 \mathrm{~cm}^{-1}$ (guaiacyl). The peak at $1030 \mathrm{~cm}^{-1}$ corresponded to the guaiacyl type units (Fig. 4). However, Kosikova and Slavikova (2004) found that the $\mathrm{C}-\mathrm{O}$ bands at 1097 and $1035 \mathrm{~cm}^{-1}$ were connected to the secondary and primary alcohols, respectively. They do not disappear because they fall together with the $\mathrm{C}-\mathrm{O}$ stretch from aliphatic ethers and the aromatic guaiacyl type $\mathrm{C}-\mathrm{H}$, respectively, both of which were unaffected by the butyration reaction.

The small peak at $822 \mathrm{~cm}^{-1}$ is attributed to the $\mathrm{C}-\mathrm{H}$ stretch vibration, and two peaks appeared at 618 and $542 \mathrm{~cm}^{-1}$ band corresponding to the $\mathrm{C}-\mathrm{H}$ bend, as shown in Fig. 4. Dirckx et al. (1992) and Schwanninger et al. (2004) also found that the aromatic $-\mathrm{CH}$ stretch vibration was detected for all wavenumbers less than $900 \mathrm{~cm}^{-1}$.

\section{Main chemical functional groups of Leucaena leucocephala stem bark}

Based on the results and discussion, the functional groups of extractives, cellulose and lignin of Leucaena leucocephala stem bark are summarized in Table 1.

Aromatic compounds were the main functional groups (Table 1). They appear sharply at 1612,1517 and $1442 \mathrm{~cm}^{-1}$ band, followed by methyl and methylene at 2918 and $2850 \mathrm{~cm}^{-1}$ wavenumber range, while a strong, broad and wide peak in the $3296 \mathrm{~cm}^{-1}$ region is dedicated to the hydroxyl group. The rest of the compounds, which existed as small peaks (carbonyl and ether), tiny (alkene) and very tiny shapes (alkane), appeared weak and less functional in the bark extractives. According to Feng et al. (2016), IR spectra of all the bark are similar with respect to the IR absorbance of some typical functional groups, i.e., (a) aromatics, (b) methylene $\left(-\mathrm{CH}_{2}-\right)$, (c) $\mathrm{C}-\mathrm{O}-\mathrm{C}$ and (d) $\mathrm{Ar}-\mathrm{CH}$.

Table 1 also lists the carbonyl and hydroxyl groups as the main functional groups of cellulose. Carbonyl and hydroxyl possess the highest intensity and sharp peak at $1017 \mathrm{~cm}^{-1}$ and broad and wide peak at $3318 \mathrm{~cm}^{-1}$, respectively. $\mathrm{H}-\mathrm{O}-\mathrm{H}$ deformation of absorbed water was observed at $1635 \mathrm{~cm}^{-1}$, while a methyl group existed in the $2899 \mathrm{~cm}^{-1}$ region. The peaks were of sharp shape and medium width. Carbon dioxide, alkyne, alkane, carbonyl and carboxyl groups, on the other hand, were present as small and tiny peaks. Apart from that, ethers, methyl and carboxyl existed as very tiny peaks and with less functionality. The formation of inter- and intra-molecular hydrogen bonds in the cellulose not only has a strong influence on the physical properties of cellulose, including solubility (Kondo et al. 1994; Kondo 1997), hydroxyl reactivity (Kondo 1997) and crystallinity (Itagaki et al. 1997), but also plays an important role in the mechanical properties of the cellulose (Kondo et al. 1994).

For lignin, carbonyl $\left(1611 \mathrm{~cm}^{-1}\right)$, carboxyl $\left(1030 \mathrm{~cm}^{-1}\right)$ and hydroxyl $\left(3319 \mathrm{~cm}^{-1}\right)$ were the main functional groups, where the peaks clearly appeared with broad, sharp and wide shapes (Table 1). The majority of the chemical function 
Table 1 Summary of the peak location and shape of the IR bands of the main chemical functional groups of L. leucocephala stem bark obtained from FTIR analysis

\begin{tabular}{|c|c|c|c|c|}
\hline \multirow{2}{*}{$\begin{array}{l}\text { Component } \\
\text { Extractive }\end{array}$} & \multirow{2}{*}{$\begin{array}{l}\begin{array}{l}\text { Peak } \\
\text { wavenumber } \\
\left(\mathrm{cm}^{-1}\right)\end{array} \\
3296\end{array}$} & \multicolumn{2}{|c|}{ Functional group } & \multirow{2}{*}{$\begin{array}{l}\text { Peak shape/size } \\
\text { Broad, width }\end{array}$} \\
\hline & & $\mathrm{OH}$ & Phenolic and aliphatic structures & \\
\hline & 2918 & $\mathrm{C}-\mathrm{H}$ & Methylene group & Broad, sharp \\
\hline & 2850 & $\mathrm{C}-\mathrm{H}$ & $\begin{array}{l}\text { Methyl, methylene and methoxyl } \\
\text { groups }\end{array}$ & Medium, sharp \\
\hline & 1735 & $\mathrm{C}-\mathrm{O}$ & Carbonyl & Shoulder \\
\hline & 1612 & $\mathrm{C}=\mathrm{C}$ & Aromatic & Broad, sharp \\
\hline & 1517 & $\mathrm{C}=\mathrm{C}$ & Aromatic & Medium, sharp \\
\hline & 1442 & $\mathrm{C}=\mathrm{C}$ & Aromatic & Broad, sharp \\
\hline & 1207 & $\mathrm{C}-\mathrm{O}-\mathrm{C}$ & Ether & Small \\
\hline & 1062 & $\mathrm{C}-\mathrm{O}$ & Carbonyl & Small \\
\hline & 1000 & $\mathrm{C}-\mathrm{OH}$ & Carboxyl & Very tiny \\
\hline & 924 & $\mathrm{C}-\mathrm{H}$ & Alkene & Tiny \\
\hline & 828 & $\mathrm{C}-\mathrm{H}$ & Alkane & Very tiny \\
\hline \multirow[t]{14}{*}{ Cellulose } & 3318 & $\mathrm{OH}$ & Hydroxyl group for alpha-cellulose & Broad \\
\hline & 2899 & $\mathrm{C}-\mathrm{H}$ & Methyl group & Medium \\
\hline & 2350 & $-\mathrm{COO}$ & Carbon dioxide & Small \\
\hline & 2129 & $\mathrm{C}=\mathrm{C}$ & Alkyne & Small \\
\hline & 2019 & $\mathrm{C}=\mathrm{C}$ & Alkene & Tiny sharp \\
\hline & 1635 & $\mathrm{H}-\mathrm{O}-\mathrm{H}$ & Adsorbed water & Medium \\
\hline & 1437 & $\mathrm{CH}_{2}$ & Alkane & Tiny \\
\hline & 1376 & $\mathrm{C}-\mathrm{H}$ & Alkane & Tiny \\
\hline & 1317 & $\mathrm{C}-\mathrm{O}$ & Carbonyl & Tiny sharp \\
\hline & 1160 & $\mathrm{C}-\mathrm{O}-\mathrm{C}$ & Ethers & Very tiny sharp \\
\hline & 1017 & $\mathrm{C}-\mathrm{O}$ & Carbonyl & High, sharp \\
\hline & 891 & $\mathrm{C}-\mathrm{H}$ & Methyl & Very tiny shoulder \\
\hline & 655 & $\mathrm{C}-\mathrm{OH}$ & Carboxyl & Asymmetric tiny shoulder \\
\hline & 582 & $\mathrm{C}-\mathrm{OH}$ & Carboxyl & Very tiny \\
\hline
\end{tabular}


Table 1 (continued)

\begin{tabular}{|c|c|c|c|c|}
\hline \multirow{2}{*}{$\begin{array}{l}\text { Component } \\
\text { Lignin }\end{array}$} & \multirow{2}{*}{$\begin{array}{l}\begin{array}{l}\text { Peak } \\
\text { wavenumber } \\
\left(\mathrm{cm}^{-1}\right)\end{array} \\
3319\end{array}$} & \multicolumn{2}{|c|}{ Functional group } & \multirow{2}{*}{$\begin{array}{l}\text { Peak shape/size } \\
\text { Broad, width }\end{array}$} \\
\hline & & $\mathrm{OH}$ & Aromatic and aliphatic $\mathrm{OH}$ groups & \\
\hline & 2927 & $\mathrm{C}-\mathrm{H}$ & $\begin{array}{l}\text { Methyl, methylene and methoxyl } \\
\text { groups }\end{array}$ & Medium \\
\hline & 2855 & $\mathrm{C}-\mathrm{H}$ & $\begin{array}{l}\text { Methyl, methylene and methoxyl } \\
\text { groups }\end{array}$ & Very tiny \\
\hline & 2182 & $\mathrm{NCO}$ & Isocyanate groups & Small sharp \\
\hline & 2053 & $\mathrm{NCO}$ & Isocyanate groups & Small sharp \\
\hline & 1948 & $\mathrm{NCO}$ & Isocyanates groups & Small sharp \\
\hline & 1611 & $\mathrm{C}=\mathrm{O}$ & Aldehyde groups & Broad, sharp \\
\hline & 1501 & $\mathrm{C}-\mathrm{H}$ & $\begin{array}{l}\text { C-H deformation (methyl and meth- } \\
\text { ylene) }\end{array}$ & Medium, sharp \\
\hline & 1447 & $\mathrm{C}-\mathrm{H}$ & $\begin{array}{l}\text { Aromatic skeletal vibration combined } \\
\text { with } \mathrm{C}-\mathrm{H} \text { in plane deformation }\end{array}$ & Medium, sharp \\
\hline & 1294 & $\mathrm{C}-\mathrm{O}$ & $\mathrm{C}-\mathrm{O}$ stretching of syringyl ring & Very tiny shoulder \\
\hline & 1241 & $\mathrm{C}-\mathrm{O}$ & $\mathrm{C}-\mathrm{O}$ stretching of guaiacyl ring & Medium \\
\hline & 1030 & $\mathrm{C}-\mathrm{OH}$ & $\begin{array}{l}\mathrm{C}-\mathrm{OH} \text { stretch vibration in Guaiacyl } \\
\text { units }\end{array}$ & Broad \\
\hline & 822 & $\mathrm{C}-\mathrm{H}$ & $\mathrm{C}-\mathrm{H}$ rock vibration & Very tiny \\
\hline & 618 & $\mathrm{C}-\mathrm{H}$ & Alkyne & Very tiny \\
\hline & 542 & $\mathrm{C}-\mathrm{H}$ & Alkanes & Tiny sharp \\
\hline
\end{tabular}

of lignin spectra is attributed to the methyl, methylene and methoxyl groups (2927, 2855, 1501 and $1447 \mathrm{~cm}^{-1}$ ), which existed in medium sharp peaks. Isocyanate and aromatic compounds were also detected in lignin as small, sharp and very tiny peaks. According to Gosselink et al. (2004), the hydroxyl, methoxyl, carbonyl, and carboxyl groups are the most important chemical functional groups in lignin, and they can be used for its identification (Shamsuri and Abdullah, 2010). However, lignin should be differentiated according to the hydroxyl groups and amine contents (Sahoo et al. 2011).

\section{Conclusion}

Leucaena leucocephala barks were characterized to determine their chemical functional groups. The extractives, cellulose and lignin of L. leucocephala bark were extracted through separation methods before the functional groups were determined. The research results found that the separation of the extractives from 
the original bark did not change the bands of the functional groups; however, the absorbance intensity weakened in the group frequency and fingerprint regions. Removal of extractives, pectin, hemicellulose and lignin from the original bark contributed indirectly to the increase in the intensity absorbance of cellulose. Broad peaks of $\mathrm{OH}$ stretching were found for all the spectra, which are attributed to the presence of phenolic $\mathrm{OH}$ and aliphatic structures of extractives and the aromatic structures of lignin. This study also contributed to the abundant information concerning hydrogen bonds, which were correlated with the scission of the intra- and inter-molecular hydrogen bonds of cellulose. Overall, the results from this study indicate that an aromatic compound is the main chemical functional group of extractives, while water, carbonyl and ether are the main components of cellulose. In addition, it was found that methyl, methylene, carbonyl and carboxyl groups are the main chemical functional groups of lignin in L. leucocephala stem bark.

Acknowledgements This research is supported by the UMS Great (GUG0217-1/2018). We thank our colleagues from the Forestry Complex Laboratory, UMS, especially Mr. Airin Termin, Mr. David Kungin, Mr. Rizan Gulam Hussein, Mr. Erwan Silin, Mr. Azli Sulid, Mr. Seliman Rajion, Mr. Rozaidi Hassan, Mr. Ahmad Dasuki, Mdm. Nermalawati Nazri, Mdm. Valenah Lawrence and from the Science Complex Laboratory, our appreciation goes to Mr. Taipin \& Mdm. Juliana for their technical support and expertise that greatly assisted the research. We also acknowledge the financial support awarded by the Ministry of Higher Education Malaysia (KPT) that provides the grant and scholarship throughout the research period.

Open Access This article is licensed under a Creative Commons Attribution 4.0 International License, which permits use, sharing, adaptation, distribution and reproduction in any medium or format, as long as you give appropriate credit to the original author(s) and the source, provide a link to the Creative Commons licence, and indicate if changes were made. The images or other third party material in this article are included in the article's Creative Commons licence, unless indicated otherwise in a credit line to the material. If material is not included in the article's Creative Commons licence and your intended use is not permitted by statutory regulation or exceeds the permitted use, you will need to obtain permission directly from the copyright holder. To view a copy of this licence, visit http://creativecommons.org/licen ses/by/4.0/.

\section{References}

Ab Rahman H, Wan Abdul Rahman WMN, Razali NA, Kassim J, Sa'ad MF, Japaruddin Y, Ogawa N (2018) Properties of fibreboard made from cultivated Leucaena leucocephala and Rubberwood. Int J Eng Technol 7(4.18):346-349

Ahmad Z, Wee LS, Fauzi MA (2011) Mechanical properties of wood-wool cement composite board manufactured using selected Malaysian fast grown timber species. ASM Sci J 5(1):27-35

American Society for Testing Materials, ASTM D1103 (2001) Standard test method for alpha-cellulose of wood. Annu Book ASTM Stand 4(10):173-174

American Society for Testing and Materials, ASTM D1105 (2001) Standard test method for preparation of extractive-free wood D1105-96 (Reapproved 2001). Annu Book ASTM Stand 4(10):177-178

American Society for Testing Materials, ASTM D1106 (2001) Standard test method for acid-insoluble lignin of wood D1106-96 (Reapproved 2001). Annu Book ASTM Stand 4(10):179-180

Babatunde A (2008) Effect of wood density on bending strength and dimensional movement of flake boards from Gmelina arborea and Leuceana leucocephala In: Proceedings 11th Int. Organicbonded Fiber Composite Conference, Madrid, 2008:260-266 
Belouadah Z, Ati A, Rokbi M (2015) Characterization of new natural cellulosic fiber from Lygeum spartum L. Carbohyd Polym 134:429-437. https://doi.org/10.1016/j.carbpol.2015.08.024

Caron A (2010) Extractives from Sitka Spruce. Dissertation, University of Glasgow, pp 161-171

Cheng SN, D'Cruz I, Yuan ZS, Wang MC, Anderson M, Leitch M, Xu CC (2011) Use of bio-crude derived from woody biomass to substitute phenol at high-substitution level for the production of bio-based phenolic resole resins. J Appl Polym Sci 121:2743-2751

Ciolacu D, Ciolacu F, Popa VI (2011) Amorphous cellulose-structure and characterization. Cellul Chem Technol 45:13-21

Conde E, Cadahia E, Diez-Barra G-V, MC, (1996) Polyphenolic composition of bark extracts from Eucalyptus camaldulensis, E. globulus and E. rudis. Holz Roh- Werkst 54:175-181. https://doi. org/10.1007/s001070050162

De Rosa IM, Kenny JM, Puglia D, Santulli C, Sarasini F (2010) Morphological, thermal and mechanical characterization of Okra (Abelmoschus esculentus) fibres as potential reinforcement in polymer composites. Compos Sci Technol 70(1):116-122

Dirckx O, Triboulot-Trouy M, Merlin A, Deglise X (1992) Changes in the color of Abies grandis wood exposed to sunlight. Ann For Sci 49:425-447

Eberhardt TL, Li X, Shupe TF, Hse CY (2007) Chinese Tallow Tree (Sapium sebiferum) Utilization: characterization of extractives and cell-wall chemistry. Wood Fiber Sci 39(2):319-324

El Mansouri NE, Salvadó J (2007) Analytical methods for determining functional groups in various technical lignins. Ind Crops Prod 26(2):116-124. https://doi.org/10.1016/j.indcrop.2007.02.006

Faix O (1992) Fourier transform infrared spectroscopy. In: Lin SY, Dence CW (eds) Methods in lignin chemistry. Springer, Berlin, pp 83-109

Fan M, Dai D, Huang B (2012). Fourier transform infrared spectroscopy for natural fibres. Fourier Transform-Materials Analysis, pp 45-68

Feng SH, Yuan ZH, Leitch M, Xu CC (2014) Hydrothermal liquefaction of barks into bio-crude-effects of species and ash content/composition. Fuel 116:214-220

Feng S, Yuan Z, Leitch M, Shui H, Xu CC (2016) Effects of bark extraction before liquefaction and liquid oil fractionation after liquefaction on bark-based phenol formaldehyde resoles. Ind Crops Prod 84:330-336. https://doi.org/10.1016/j.indcrop.2016.02.022

Fengel D, Wegener G (1984) Wood: chemistry, ultrastructure reactions. Walter de Gruyter, Berlin, pp 240-265

Ferreira R, Garcia H, Sousa AF, Freire CSR, Silvestre AJD, Rebelo LPN, Pereira CS (2013) Isolation of suberin from birch outer bark and cork using ionic liquids: a new source of macromonomers. Ind Crops Prod 44:520-527. https://doi.org/10.1016/j.indcrop.2012.10.002

Fiore V, Scalici T, Valenza A (2014) Characterization of a new natural fiber from Arundo donax L. as potential reinforcement of polymer composites. Carbohyd Polym 106:77-83

Ghitescu R, Volf I, Carausu C, Bühlmann A, Gilca IA, Popa VI (2015) Optimization of ultrasoundassisted extraction of polyphenols from spruce wood bark. Ultrason Sonochem 22:535-541. https:// doi.org/10.1016/j.ultsonch.2014.07.013

Gonzalez-Vila FJ, Tinoco P, Almendros G, Martin F (2010) Pyrolysis-GC-MS analysis of the formation and degradation stages of charred residues from lignocellulosic biomass. J Agric Food Chem 49(3):1128-1131

Gosselink RJA, Abächerli A, Semke H, Malherbe R, Käuper P, Nadif A, Dam JEG, Van, (2004) Analytical protocols for characterisation of sulphur-free lignin. Ind Crops Prod 19:271-281. https://doi. org/10.1016/j.indcrop.2003.10.008

Guo X, Zhang S, Shan X (2008) Adsorption of metal ions on lignin. J Hazard Mater 151(1):134-142. https://doi.org/10.1016/j.jhazmat.2007.05.065

Indran S, Raj RE, Sreenivasan V (2014) Characterization of new natural cellulosic fiber from Cissus quadrangularis root. Carbohyd Polym 110:423-429

Itagaki H, Tokai M, Kondo T (1997) Physical gelation process for cellulose whose hydroxyl groups are regioselectively substituted by fluorescent groups. Polymer 38(16):4201-4205

Khan MA, Masudul Hassan M, Drzal LT (2005) Effect of 2-hydroxyethyl methacrylate (HEMA) on the mechanical and thermal properties of jute-polycarbonate composite. Compos A Appl Sci Manuf 36(1):71-81

Kondo T (1997) The assignment of IR absorption bands due to free hydroxyl groups in cellulose. Cellulose 4(4):281-292

Kondo T, Sawatari C, Gray MRSJ, DG, (1994) Characterization of hydrogen bonding in cellulose-synthetic polymer regioselectively substituted methylcellulose. Macromolecules 27(1):210-215 
Košikova B, Slavikova E (2004) Biotransformation of lignin polymers derived from Beech wood pulping by Sporobolomyces roseus isolated from leafy material. Biotech Lett 26:517-519

Kothiyal V, Raturi A, Kaler A (2012) Klason lignin estimation in Leucaena leucocephala by near infrared spectroscopy for selection of superior material for pulp and paper. J Indian Acad Wood Sci 9(2):105-114. https://doi.org/10.1007/s13196-012-0078-z

Lee WJ, Lan WC (2006) Properties of resorcinol-tannin-formaldehyde copolymer resins prepared from the bark extracts of Taiwan Acacia and China Fir. Biores Technol 97:257-264. https://doi. org/10.1016/j.biortech.2005.02.009

Li R, Fei J, Cai Y, Li Y, Feng J, Yao J (2009) Cellulose whiskers extracted from mulberry: a novel biomass production. Carbohyd Polym 76(1):94-99. https://doi.org/10.1016/j.carbpol.2008.09.034

Liu L, Cao J, Huang J, Cai Y, Yao J (2010) Extraction of pectins with different degrees of esterification from Mulberry branch bark. Biores Technol 101(9):3268-3273. https://doi.org/10.1016/j.biort ech.2009.12.062

Liu L, Jiang T, Yao J (2011a) A two-step chemical process for the extraction of cellulose fiber and pectin from Mulberry branch bark efficiently. Polym Environ 19:568-573. https://doi.org/10.1007/s1092 4-011-0300-x

Liu Q, Zhong Z, Wang S, Luo Z (2011b) Interactions of biomass components during pyrolysis: a TGFTIR study. J Anal Appl Pyrol 90:213-218. https://doi.org/10.1016/j.jaap.2010.12.009

Marzuki AR, Rahim S, Hamidah M, Ahmad Ruslan R (2011) Effects of wood: cement ratio on mechanical and physical properties of three-layered cement-bonded particleboards from Leucaena leucocephala. J Trop For Sci 23(1):67-72

Miao X, Lin J, Tian F, Li X, Bian F, Wang J (2016) Cellulose nanofibrils extracted from the byproduct of cotton plant. Carbohyd Polym 136:841-850. https://doi.org/10.1016/j.carbpol.2015.09.056

Morán JI, Alvarez VA, Cyras VP, Vázquez A (2008) Extraction of cellulose and preparation of nanocellulose from sisal fibers. Cellulose 15:149-159

MTIB (2017) Malaysian Timber Industry Board (MTIB). Forest Plantation Programme. Retrieved from MTIB: http://www.mtib.gov.my/index.php?option=com_content\&view=article\&id=94. Accessed 3rd July 2017

Niokhor P, Stevanovic T, Cloutier A (2009) Study on chemical composition, antioxidant and anti-inflammatory activities of hot water extract from Picea mariana bark and its proanthocyanidin-rich fractions. Food Chem 113(4):897-902. https://doi.org/10.1016/j.foodchem.2008.08.016

Pereira H, Graca J, Rodrigues JC (2003) Wood chemistry in relation to quality. In: Barnett JR, Jeronimidis $\mathrm{G}$ (eds) Wood quality and its biological basis, vol 3. CRC Press. Blackwell Publishing, Oxford, pp 53-83

Pietarinen SP, Willfor SM, Ahotupa MO, Hemming JE, Holmbom BR (2006) Knotwood and bark extracts: strong antioxidants from waste materials. J Wood Sci 52:436-444. https://doi. org/10.1007/s10086-005-0780-1

Reddy KO, Ashok B, Reddy KRN, Feng Y, Zhang J, Rajulu AV (2014) Extraction and characterization of novel lignocellulosic fibers from Thespesia lampas plant. Int $\mathrm{J}$ Polym Anal Charact 19(1):48-61

Roggo Y, Chalus P, Maurer L, Lema-martinez C, Jent N (2007) A review of near infrared spectroscopy and chemometrics in pharmaceutical technologies. J Pharm Biomed Anal 44:683-700. https://doi.org/10.1016/j.jpba.2007.03.023

Rutherford DW, Wershaw RL, Rostad CE, Kelly CN (2012) Effect of formation conditions on biochars: compositional and structural properties of cellulose, lignin and pine biochars. Biomass Bioenerg 46:693-701. https://doi.org/10.1016/j.biombioe.2012.06.026

Sahoo S, Seydibeyoglu MO, Mohanty AK, Misra M (2011) Characterization of industrial lignins for their utilization in future value added applications. Biomass Bioenerg 35:4230-4237. https://doi. org/10.1016/j.biombioe.2011.07.009

Salim R, Asik, J, Sarjadi, MS (2019) Acidity, solubility and chemical utilization of local Leucaena leucocephala stem bark. J Mech Eng Res Dev 42:194-201. https://doi.org/10.26480/jmerd 05.2019.194.201

Saravanakumar SS, Kumaravel A, Nagarajan T, Sudhakar P, Baskaran R (2013) Characterization of a novel natural cellulosic fiber from Prosopis juliflora bark. Carbohyd Polym 92(2):1928-1933. https://doi.org/10.1016/j.carbpol.2012.11.064

Sathishkumar T, Navaneethakrishnan P, Shankar S, Rajasekar R (2013) Characterization of new cellulose Sansevieria ehrenbergii fibers for polymer composites. Compos Interf 20(8):575-593 
Schaber PM, Colson J, Higgins S, Thielen D, Anspach B, Brauer J (2004) Thermal decomposition (pyrolysis) of urea in an open reaction vessel. Thermochim Acta 424:131-142

Schwanninger M, Rodrigues JC, Pereira H, Hinterstoisser B (2004) Effects of short-time vibratory ball milling on the shape of FT-IR spectra of wood and cellulose. Vib Spectrosc 36:23-40

Seki Y, Sarikanat M, Sever K, Durmus Kahya C, (2013) Extraction and properties of Ferula communis (chakshir) fibers as novel reinforcement for composites materials. Compos B Eng 44(1):517-523

Sen A, Miranda I, Santos S, Graca J, Pereira H (2010) The chemical composition of cork and phloem in the rhytidome of Quercus cerris bark. Ind Crops Prod 31:417-422. https://doi.org/10.1016/j.indcr op.2010.01.002

Shameli K, Ahmad M, Al-mulla EAJ, Ibrahim NA, Shabanzadeh P, Rustaiyan A, Zidan M (2012) Green biosynthesis of silver nanoparticles using Callicarpa maingayi stem bark extraction. Molecules 17:8506-8517. https://doi.org/10.3390/molecules17078506

Shamsuri AA, Abdullah DK (2010) Isolation and characterization of lignin from rubber wood in ionic liquid medium. Mod Appl Sci 4(11):19-27

Shi H, Fatehi P, Xiao H, Ni Y (2011) A combined acidification/PEO flocculation process to improve the lignin removal from the pre-hydrolysis liquor of kraft-based dissolving pulp production process. Biores Technol 102(8):5177-5182. https://doi.org/10.1016/j.biortech.2011.01.073

Sinha E, Rout S (2009) Influence of fibre-surface treatment on structural, thermal and mechanical properties of jute fibre and its composite. Bull Mater Sci 32(1):65-76

Soto R, Freer J, Baeza J (2005) Evidence of chemical reactions between di- and poly-glycidyl ether resins and tannins isolated from Pinus radiata D. Don Bark Bioresour Technol 96:95-101

Subramanian K, Kumar PS, Jeyapal P, Venkatesh N (2005) Characterization of lignocellulosic seed fibre from Wrightia Tinctoria plant for textile applications-An exploratory investigation. Eur Polymer J 41(4):853-861

Sun XF, Xu F, Sun RC, Fowler P, Baird MS (2005) Characteristics of degraded cellulose obtained from steam-exploded wheat straw. Carbohydr Res 340:97-106

Tian M, Wen J, MacDonald D, Asmussen RM, Chen A (2010) A novel approach for lignin modification and degradation. Electrochem Commun 12(4):527-530. https://doi.org/10.1016/j.eleco m.2010.01.035

Tsuchikawa S (2007) A review of recent near infrared research for wood and paper. Appl Spectrosc Rev 42(1):43-71. https://doi.org/10.1080/05704920601036707

Valentín L, Kluczek-turpeinen B, Willfor S, Hemming J, Hatakka A, Steffen K, Tuomela M (2010) Scots pine (Pinus sylvestris) bark composition and degradation by fungi: potential substrate for bioremediation. Biores Technol 101(7):2203-2209. https://doi.org/10.1016/j.biortech.2009.11.052

Wahab MA, Jellali S, Jedidi N (2010) Ammonium biosorption onto sawdust: FTIR analysis, kinetics and adsorption isotherms modeling. Biores Technol 101(14):5070-5075. https://doi.org/10.1016/j.biort ech.2010.01.121

Wan Mohd Nazri WAR, Jamaludin K, Rudaini MN, Rahim S, Nur Yuziah MY (2009) Effect of chemical components on properties of oriented strand board from "Leucaena leucocephala" wood. J Trop For Sci 21(4):353-360

Williams DH, Fleming I (1989) Spectroscopic method in organic chemistry, 4th edn. McGraw Hill Higher Education, United States, pp 85-121

Xavier D, Emmanuel F, Philippe G, Eric M (2012) Spruce bark hydrolysis to optimize phenolic content. Cellul Chem Technol 46(9-10):541-550

Yang L, Sun X, Yang F, Zhao C, Zhang L, Zu Y (2012) Application of ionic liquids in the microwaveassisted extraction of proanthocyanidins from Larix gmelini bark. Int J Mol Sci 13:5163-5178. https ://doi.org/10.3390/ijms 13045163

Zhao Y, Yan N, Feng MW (2013) Thermal degradation characteristics of phenol-formaldehyde resins derived from beetle infested pine barks. Thermochim Acta 555:46-52. https://doi.org/10.1016/j. tca.2012.12.002

Publisher's Note Springer Nature remains neutral with regard to jurisdictional claims in published maps and institutional affiliations. 


\section{Authors and Affiliations}

\section{Rafidah Md Salim ${ }^{1}$ (D) Jahimin Asik ${ }^{2}$ Mohd Sani Sarjadi ${ }^{2}$}

$\triangle$ Rafidah Md Salim

rafidahs@ums.edu.my

1 Wood Chemistry Laboratory, Forestry Complex, Faculty of Science and Natural Resources, Universiti Malaysia Sabah, UMS Road, Kota Kinabalu, Sabah 88400, Malaysia

2 Industrial Chemistry Department, Science Complex, Faculty of Science and Natural Resources, Universiti Malaysia Sabah, UMS Road, Kota Kinabalu, Sabah 88400, Malaysia 